\title{
EL CASO BREIVIK COMO PARADIGMA DE LA NUEVA VIOLENCIA POLÍTICA EN EUROPA
}

\author{
Jesús Pérez ${ }^{1}$ \\ Universidad Nacional de Educación a Distancia (UNED)
}

\begin{abstract}
Resumen:
Tras el doble atentado en Noruega del 22 de julio de 2011 cometido por Anders Behring Breivik, el terrorismo en Europa se enfrenta a una nueva amenaza. La novedad ideológica de Breivik es escasa, salvo por actualizar peligros que parecían del pasado. Por el contrario, su novedad operativa sí es relevante, ya que demuestra la posibilidad de la actuación de "lobos solitarios" en Europa y ejemplifica de qué manera el occidental medio puede actuar con un potencial muy alto de causar daños. Se concluye con el avance de un nuevo paradigma, el de sujetos que actúan movidos políticamente por un objetivo irrealizable, para favorecer a grupos que son extremadamente abstractos o no existen, lo que les proporciona un blindaje ideológico sin capacidad alta de movilización pero con destacadas cotas de destrucción.
\end{abstract}

Palabras clave: violencia política, terrorismo, lobo solitario, extrema derecha, neo-tradicionalismo.

Title in English: "The Breivik Case as Paradigm of the new Political Violence"

Abstract:

After the double attack in Norway on July 22, 2011, committed by Anders Behring Breivik, terrorism in Europe is facing a new threat. This article points out that Breivik's ideological novelty is not relevant, except for updating past dangers. However, his operational novelty itself must be highlighted for both demonstrating the possibility of "lone wolves" in Europe and showing how every citizen could act to cause a high damage. The article concludes advancing a new paradigm, which can consist in terrorists which are politically motivated by unachievable goals, to promote groups that are extremely abstract or non-existent. That paradigm shows a kind of terrorist with a powerful ideological shield, without capacity of mobilization but with outstanding levels of destruction.

Keywords: Political Violence, Terrorism, Lone Wolf, Far Right, Neo-Traditionalism.

Copyright (C) UNISCI, 2014.

The views expressed in these articles are those of the authors, and do not necessarily reflect the views of UNISCI. Las opiniones expresadas en estos artículos son propias de sus autores, y no reflejan necesariamente la opinión de UNISCI.

\footnotetext{
${ }^{1}$ Jesús Pérez es Licenciado en Derecho por la Universidad de Valencia y en Periodismo por la Universidad Carlos III y Especialista en Gestión de Crisis y Experto en Crimen Organizado por el Instituto Universitario General Gutiérrez Mellado. Es Doctorando en Derecho Penal por la UNED.

E-mail: nessoneuman@gmail.com.
} 


\section{Introducción}

Las elecciones noruegas de septiembre de 2013 han devuelto a la actualidad a Anders Behring Breivik. El Partido del Progreso, donde militó el autor de los atentados de julio de 2011 en Oslo y Utoya, tras obtener el $16.3 \%$ de los votos, tiene la posibilidad por primera vez de entrar en el gobierno como parte de una coalición contra el Partido Socialista saliente, lo que ha sido interpretado, cuanto menos, como una de las frecuentes paradojas que deja la política $\mathrm{y}$, en general, como un espaldarazo relativo a algunas de las tesis del terrorista, principalmente en materia de inmigración ${ }^{2}$.

Sin embargo, estas interpretaciones son inexactas, entre otros motivos porque ese partido ha perdido más de seis puntos respecto a los anteriores comicios de 2009, donde logró un $22.9 \%$, el mejor resultado de su historia ${ }^{3}$. Por tanto, si quiere verse en clave electoral, la acción de Breivik ha sido dañina para la citada formación. Además, aunque el partido introdujo en el debate político noruego el término "islamización sigilosa", su visión en esa materia es conservadora, en oposición a su retórica ${ }^{4}$ y, sin duda, alejada de la ideología del terrorista.

Así, a dos años del atentado, tanto una hipotética relación entre la violencia política de Breivik y la ideología del Partido del Progreso, como, por ejemplo, la discusión sobre la calificación jurídica de los atentados (¿terrorismo o crímenes contra la humanidad?) ${ }^{5}$, son puntos que merecen un análisis detenido y que todavía plantean interrogantes. Sin embargo, este artículo se centra en otros dos aspectos, quizás aún más relevantes para la seguridad en Europa: Las características ideológicas y la novedad operativa de estos atentados.

\footnotetext{
${ }^{2}$ Por todos, véase Paterson, Tony: "Norway election results: Anti-inmigrant party with links to mass murderer Anders Behring Breivik set to enter government under Conservative leader Erna Solberg”, The Independent, 10 de septiembre de 2013, en http://www.independent.co.uk/news/world/europe/norway-election-resultsantiimmigrant-party-with-links-to-mass-murderer-anders-behring-breivik-set-to-enter-government-underconservative-leader-erna-solberg-8805649.html.

${ }^{3}$ Como destaca la propia formación en su web: The Progress Party web, 22 de septiembre de 2013, en http://www.frp.no/nor/The-Progress-Party/History.

${ }^{4}$ Knutsen, Leif: “Is Norway's Progress Party making progress?”, The Foreigner, en http://theforeigner.no/pages/columns/is-norways-progress-party-making-progress/.

${ }_{5}^{5}$ Breivik fue condenado a 21 años de prisión por el delito de terrorismo, pero llegó a plantearse si se le podría acusar de crímenes contra la humanidad. Véase, Poza, Pedro: "Breivik, condenado a 21 años de prisión por la muerte de 77 personas", El Mundo, 24 de agosto de 2012, en

http://www.elmundo.es/elmundo/2012/08/24/internacional/1345764460.html y Serbeto, Enrique, "El fiscal planea acusar a Breivik de crímenes contra la humanidad", $A B C, 27$ de julio de 2013, en http://www.abc.es/20110727/internacional/abcp-fiscal-planea-acusar-breivik-20110727.html. El debate sobre la expansión del tipo penal de crímenes contra la humanidad al terrorismo es complejo y sería materia de otro artículo. En general, para una posición fundamentada de por qué los atentados de Noruega no fueron crímenes contra la humanidad, por su carácter aislado y alejamiento del tipo penal consolidado en la doctrina, véase Schabas, William: “Crimes Against Humanity in Norway?", PhD studies in human rights, 26 de julio de 2011, en http://humanrightsdoctorate.blogspot.mx/2011/07/crimes-against-humanity-in-norway.html. Sobre el concepto de crímenes contra la humanidad, véase, desde una perspectiva jurídica, Gil, Alicia (1999): Derecho penal internacional, Madrid, Tecnos, p. 151 y filosófica, Luban, David: "A Theory of Crimes Against Humanity”, The Yale Journal of International Law, vol. 29, nº 1 (2004), p. 108.
} 


\section{Discurso ideológico: No sólo Bickle o Hitler ${ }^{6}$}

La reflexión sobre los atentados de Oslo y Utoya oscila entre considerarlos la acción de un criminal desequilibrado o la de un fanático político, y si el matiz político es lo suficientemente marcado como para provocar emuladores que compartan su proyecto. Dicho gráficamente, se debate entre considerar a Breivik un Travis Bickle ${ }^{7}$ o un Adolf Hitler.

En este texto se argumenta que la actuación de Breivik fue un acto de violencia política, con la que quería provocar un cambio social, declarado en el Manifiesto "2083. Una Declaración Europea de Independencia"8. Una diferencia clave entre el crimen ordinario y la violencia política es que ésta quiere provocar un efecto de emulación, al facilitar una serie de variables ideológicas y operacionales. A modo de enumeraciones contrapuestas ${ }^{9}$, el citado doble atentado tiene más que ver ideológicamente con la extrema derecha centrada en el odio a la izquierda y a los musulmanes que con el neo nazismo y el racismo, con las guerras de religión que con el cristianismo; y en su modus operandi, con la inmediatez de la mística de la violencia y el pensamiento conspirativo que con una estrategia, con los "lobos solitarios" que con las organizaciones terroristas. Sin negar la presencia, en menor medida, de las segundas partes de la enumeración, el terrorista de Oslo bebe ideológicamente de los primeros términos, es decir, su ideología es una extrema derecha sui generis ${ }^{10}$, projudía y antimusulmana, idealizadora del pasado europeo, que se vale del terrorismo como modelo para crear o acelerar una situación en la que se impongan sus objetivos de una Europa sin musulmanes ni personas con ideas diferentes a las suyas, para lograr que el viejo continente recupere lo que él considera sus raíces.

De esa descripción se deduce tanto el marco ideológico desde el que actúa, como sus antecedentes ideológicos, algunos inmediatos y otros más lejanos. El marco ideológico de Breivik es occidental. Proviene de una tradición que, desde la Revolución Francesa, considera

\footnotetext{
6 "Como dice una vieja máxima de Thomas Szasz, desde un punto de vista científico, la diferencia entre la violencia política y la violencia común es la misma que hay entre el agua común y el agua bendita”. Ruggiero, Vincenzo (2009): La violencia política. Un análisis criminológico, Rubí, Anthropos Editorial, p.3.

${ }^{7}$ Nombre que hace referencia al sociópata protagonista del filme de Martin Scorsese, "Taxi driver".

8"2083. A European Declaration of Independence", en http://es.scribd.com/doc/60740932/2083-a-EuropeanDeclaration-of-Independence.

En él se describe el ascenso cultural del marxismo/multiculturalismo en Europa Occidental, seguido de un repaso histórico a la supuesta colonización e islamización del continente, en qué situación está la "resistencia" frente a ella y cómo combatir y revertir la situación. Véase Ibid., pp. 12-13. El apartado "Planeando la operación", que aborda aspectos logísticos, cubre Ibid., pp. 849-948.

${ }^{9}$ Conforme al ejemplo de Arquilla y Ronfeldt, que para explicar qué es la guerra en red afirman que "tiene más relación con los zapatistas que con los fidelistas, con Hamás que con la Organización para la Liberación de Palestina (OLP), con el movimiento American Christian Patriot que con el Ku Klux Klan, y más con las triadas asiáticas que con la Cosa Nostra". Véase Arquilla, John, y Ronfeldt, David: "La aparición de la 'guerra en red' (revisado)", en Arquilla, John y Ronfeldt David (eds.) (2003): Redes y guerras en red. El futuro del terrorismo, el crimen organizado y el activismo político, Madrid, Alianza Editorial, pp. 36-37.

10 "El ultranacionalismo conservador de Breivik se encuadra sin duda en la extrema derecha. Sin embargo, no es sencillo encontrar un lugar suficientemente cómodo para tal amalgama de filias y fobias en las corrientes mayoritarias de dicha tendencia política. Esta circunstancia encaja con la figura de los "lobos solitarios", que suelen crear sus propias ideologías combinando aversiones personales con objetivos políticos y sociales de carácter más amplio”. Jordán, Javier: “Anders Behring Breivik: algunas consideraciones sobre la figura del 'lobo solitario' terrorista", Grupo de Estudios sobre Política y Seguridad Internacional, 27 de julio de 2011, en http://seguridadinternacional.es/?q=node/24. Este tipo de terroristas suele carecer de las dotes sociales necesarias para insertarse en una organización terrorista. Véase Sageman, Marc (2004): Understanding terror networks, Philadelphia, University of Pennsylvania, pp. 81 y ss.
} 
que es posible remodelar la sociedad con una serie de actos lo suficientemente decididos ${ }^{11}$. Esta visión dio lugar, ya a finales del siglo XIX, a los terroristas modernos, con los que Breivik comparte rasgos como la desconfianza en un alzamiento popular, al menos a corto plazo, del que se deriva la necesidad de la violencia terrorista para cambiar la historia ${ }^{12}$; o la reverencia por la ciencia aplicada a las armas, que extienden el poder de destrucción a cualquier hombre ${ }^{13}$.

A partir de ese marco específicamente occidental, entre sus antecedentes ideológicos más inmediatos están los movimientos de extrema derecha europeos. Su actuación recuerda a los notorios grupos extremistas que actuaron en la posguerra española y que, autónomamente o insertos en estructuras más o menos ligadas a los Estados, realizaron atentados para estremecer a la sociedad y prevenir que ésta virase hacia la izquierda. Actualmente, la extrema derecha europea ha pasado a caracterizarse por un discurso contra la inmigración y el Islam, dentro de la democracia. Aunque comparta cierto poso ideológico con estos conservadores, al analizar cómo interactúan los musulmanes (en sentido amplio: gobiernos de origen de los inmigrantes, autoridades religiosas, inmigrantes) con el establishment político europeo, Breivik considera que se han resignado a la llegada de inmigrantes musulmanes, por un pacto tácito o expreso para conquistar Europa. A ello se añade la tesis de que el conservadurismo ha perdido una supuesta guerra cultural ante el marxismo, que estaría copiado del Manifiesto de Unabomber, si bien, como se ha dicho, intercambiando sujetos ${ }^{14}$.

\footnotetext{
11 “Lo que sostendremos aquí es que el terrorismo se halla mucho más íntimamente conectado con la moderna tradición democrática liberal de lo que tal concepción implicaría [...]

El primer supuesto apareció cuando el vasto programa de destrucción de la Revolución Francesa llevó a los hombres a creer que está dentro del poder de su voluntad rehacer de arriba abajo la sociedad, y hasta remodelar la propia naturaleza humana.

El segundo supuesto era que el hombre es naturalmente bueno [...] Esto significaba que, de ser una actividad en la que los hombres sólo buscaban un marco estable del orden dentro del cual hacer sus vidas, la política se elevó al rango de una cruzada casi religiosa, cuya meta era despertar 'al pueblo' de su largo sueño histórico e inspirarlo para que se librase de sus opresores.

En tercer lugar, [...] [1]a doctrina de la soberanía popular proclamada por la Declaración de los Derechos del Hombre y del Ciudadano. De acuerdo con esta doctrina, el poder sólo es legítimo si es conferido 'desde abajo', por el pueblo". O’Sullivan, Noel: “Terrorismo, ideología y democracia”, en O’Sullivan, Noel (ed.) (1987): Terrorismo, ideología y revolución, Madrid, Alianza Editorial, pp. 23-25.

12 Ibid., pp. 29 y ss.

${ }^{13}$ Ibid., pp. 31 y ss. Así, "un ejemplo de hasta qué punto Breivik está en lo más fashion del terror es que su manifiesto explora la posibilidad de lanzar bombas electromagnéticas (página 956), que son las armas de destrucción masiva que ahora mismo más obsesionan a los gobiernos de Estados Unidos y China. ¿Qué es una bomba electromagnética? Es un ataque que desencadena enormes cantidades de energía electromagnética, destruyendo todos los equipos eléctricos y electrónicos del objetivo. Puede conseguirse ese efecto sobre una ciudad, un país o incluso un continente entero haciendo detonar un arma nuclear a la suficiente altitud, fuera de la atmósfera terrestre.

No se conoce ninguna defensa contra este tipo de ataque, que sólo requiere una bomba nuclear de tamaño medio, accesible para gran número de países y organizaciones terroristas a día de hoy, y un cohete capaz de propulsarla fuera de la atmósfera.

[...]Los efectos de una bomba electromagnética sobre los seres humanos son enormemente dañinos, pero no provocan la muerte automática. Servirían más como método de tortura que de asesinato. En cambio pueden destruir masivamente las infraestructuras y hasta la entera economía de un país”. Grau, Anna: “Algunas claves de lo de Noruega que da miedo saber", Piensa lo peor (ABC), 25 de julio de 2011, en http://www.abc.es/blogs/espias-espionaje/public/post/algunas-claves-de-lo-de-noruega-que-da-miedo-saber9450.asp.

${ }^{14}$ Hough, Andrew: "Norway shooting: Anders Behring Breivik plagiarised 'Unabomber"', The Telegraph, 24 de julio de 2011, en

http://www.telegraph.co.uk/news/worldnews/europe/norway/8658269/Norway-shooting-Anders-Behring-

Breivik-plagiarised-Unabomber.html. Para la influencia no sólo de Unabomber, sino de pensadores anti
} 
Entre los antecedentes más lejanos está el culto al orden o a lo militar del nazismo, e incluso una glorificación del guerrero europeo que, al remitirse a unos valores pasados le ligaría al neotradicionalismo que ve Jason Burke en los talibanes ${ }^{15}$. De esa ortopraxia ${ }^{16}$ deduce, por ejemplo, que no debería escucharse música mainstream, al igual que los talibanes deducían de los textos musulmanes que no se podían volar cometas; ambos lo prohibían por un supuesto efecto corruptor.

Esta mitificación de los valores europeos, por contraposición a los musulmanes, da lugar a un contexto inmediato de confrontación, maniqueo, de guerra de religión eterna, de un pensamiento implacable ${ }^{17}$ en el que se observa "una aspiración a la inocencia en la vinculación sin grietas con un gran proyecto de implantación de ciertos ideales absolutos en el mundo" $"$. El pensamiento contenido en el Manifiesto recuerda, pasado por un refrito histórico y académico, al descrito en "The Turner Diaries", de William Pierce, que sirvió de inspiración a Timothy Mc Veigh, el terrorista de Oklahoma, en el que se describía una batalla apocalíptica entre el Gobierno y una guerrilla de luchadores por la libertad, llamada la Orden ${ }^{19}$; en el caso que nos ocupa, una lucha de los Justiciar Knights, sujetos jueces, jurados y verdugos, que preparan la regeneración de Europa, grupo del que Breivik sería la vanguardia $^{20}$. También el yihadismo rebosa de ese misticismo de la lucha, que inventa campos de batalla o idealiza los ya existentes ${ }^{21}$.

islámicos norteamericanos, véase Shane, Scott: "Killings in Norway Spotlight Anti-Muslim Thought In U.S.”, The New York Times, 24 de julio de 2011, en http://www.nytimes.com/2011/07/25/us/25debate.html.

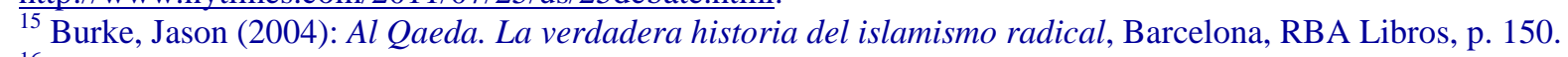

${ }^{16}$ Esto es, el control del día a día tan característico de los wahabitas, según Idem.

${ }^{17}$ Del Águila, Rafael: "Políticas perfectas: Ideales, moralidad y juicio", en Blanco, Amalio; Del Águila, Rafael y Sabucedo, José Manuel (eds.) (2005): Madrid 11-M. Un análisis del mal y sus consecuencias, Madrid, Editorial Trotta, pp. 20-21.

${ }^{18}$ Ibid., p. 21, donde se concluye que "de esa inocencia de donde procede el horror definitivo: la fuerza para el mal". En esta línea, "se requiere una enorme cantidad de arrogancia moral para justificar la destrucción de propiedad a gran escala o para tolerar un acto brutal sobre otra vida, especialmente de alguien que apenas se conoce y contra quien uno no tiene una hostilidad personal". Juergensmeyer, Mark (2001): Terrorismo religioso. El auge global de la violencia religiosa, Madrid, Siglo XXI de España Editores, S.A., p. 12. El uso abrasivamente frío de la lógica y de las cifras, el cálculo de los supuestos crímenes cometidos por los musulmanes y los que cometerán hasta 2020 ("2083. A European Declaration of Independence”, op. cit., pp. 489-490), el de las personas que deberían morir para saldar las culpas de las naciones (categorías A, B, C y D, con sus correspondientes ratios por países según los grados de infiltración del marxismo/multiculturalismo e islamismo (Ibid.,pp. 940-943), o el principio de proporcionalidad que se debería seguir respecto a estos sujetos (Ibid.,p.848), son ejemplos que remiten no sólo al nazismo, sino a la situación que Anthony Beevor recuerda se daba en el Ejército Rojo en plena caída de Berlín: "Otro método para difundir el odio que empleaban los agentes políticos era el 'marcador de la venganza'. 'Se entrevistaba a los soldados y oficiales de cada regimiento para sacar a relucir las atrocidades y los actos de 'saqueo y violencia de las bestias de Hitler'. Así, por ejemplo, en cierto batallón se elaboró un 'marcador de la venganza' en un cartel en el que se leía: 'Nos estamos vengando de la muerte de 775 familiares, del secuestro y esclavitud en Alemania de 909, de la quema de 478 casas y de la destrucción de 303 granjas"”. Beevor, Anthony (2002): Berlín. La caída: 1945, Barcelona, Crítica, p.190. Es decir, Breivik se consideraba en guerra.

${ }^{19}$ Juergensmeyer, op. cit., pp. 35-36.

${ }^{20}$ En el libro de Pierce, el protagonista era un tercero, mientras que en el Manifiesto, el protagonista es el mismo Breivik, si bien el yo narrativo a veces pasa a ser también en tercera persona, como en el diálogo que tienen consigo mismo en "2083. Una Declaración Europea de Independencia”, op. cit., pp. 1351-1415, donde, junto a juicios históricos, políticos, etc, detalla también aspectos de su personalidad.

21 "Parlin no se olvidó de Yusuf Galán, su amigo inseparable. Su último verano en España lo pasaron juntos entrenando kárate y viendo en su casa sangrientos vídeos de combates en Bosnia y Chechenia. Unas películas que les fascinaban. Muy pronto comunicó con él desde su refugio secreto en Indonesia. Lo hizo mediante correo electrónico y le envió una larga carta en la que explicaba la historia de Poso y de sus hombres. La misiva rebosaba melancolía y describía aquel escenario como una selva tropical con tierra fértil y montañas: 'Aún me 
Entonces, ¿qué quería Breivik? Su intención era, a corto plazo, propagandística. A largo plazo, ser el primero de una serie de "soldados" que "reconquistarán" Europa. El objetivo a largo plazo es delirante ${ }^{22}$, por lo que sólo el rasgo propagandístico puede considerarse relevante. En este sentido, su novedad ideológica es escasa. La radicalización del discurso anti musulmán en Europa es algo habitual. De hecho, en Noruega, el Partido del Progreso del que, como se ha dicho, fue militante Breivik $^{23}$, mantiene un discurso muy crítico con la inmigración. Quizá la particularidad esté en la cooptación de Israel al discurso de extrema derecha, si bien es el contraste al discurso de los yihadistas, que ven a europeos e israelíes como un todo. Si se tuviera que establecer el principal rasgo ideológico del discurso tendría que ver con esa cara B de la yihad: Breivik acepta que debe combatirse a los musulmanes (frente a la yihad, cruzada), pero en el propio suelo europeo, para recuperar los viejos valores del continente. Es un objetivo con un matiz religioso importante, pero que se mantiene en la órbita política.

\section{Modus operandi: lobos solitarios en Europa}

La figura del terrorista individual es algo nuevo en Europa, pero no en EEUU. El modus operandi de Breivik puede verse como un punto entre dos extremos. En uno de ellos, estaría Timothy Mc Veigh, que en el atentado de Oklahoma actuó solo, pero con el trasfondo de movimiento político que pretende justificar su actitud, las milicias de extrema derecha estadounidense $^{24}$. Su modo de actuar concuerda con el método del terrorista con un objetivo

acuerdo aquella noche del mes de Ramadán, diciembre de 1998, en que me invitaste a tu casa a media noche... Al final me encuentro aquí y tú allí. Éste es un lugar que seguro jamás te imaginas... Tal vez te suena el nombre de la isla, Celebes según los occidentales, y Sulawesi para nosotros. Es una isla única que tiene una forma muy rara... En la ciudad donde estoy, Poso, en el centro y sus alrededores antes vivían tribus indígenas aunque en la zona costera el contacto con los Bugis les convirtieron en mayoría musulmana. Los misioneros empezaron a meter las narices en Poso a mediados del siglo XIX... Tradujeron la Biblia a la lengua nativa y estaban equipados con la mejor tecnología",, Irujo, José María (2005): El agujero. España invadida por la yihad, Madrid, Santillana Ediciones Generales, S.L, p. 67. "La misiva describía la dureza de la zona: "hace mucho calor, humedad y hay mosquitos que parecen helicópteros', pero su objetivo principal era reclamar ayuda. 'Si hay rifles, no tenemos balas. En el primer día de ataque el teléfono estaba cortado porque no teníamos pelas para pagar el retraso de tres meses. Vosotros podéis hacer muchas cosas aquí. Por tan sólo cinco millones de pesetas podemos comprar una isla de doscientas hectáreas que nos sería muy útil. Pero nuestra necesidad principal son las armas...' Y se despidió así: 'Recuerda que todo lo que hacemos debe enfocar hacia la yihad... Te quiero por Alá"; Ibid., p. 68.

${ }^{22}$ Quien considere, con razón, que el Putch de Hitler también lo fue, pero haga analogías, habría que decir que la situación de la Alemania no es similar a la de Noruega/Europa actual, y sobre todo, la crisis europea si bien tiene un matiz político, es más bien de desencanto que de diferentes ideologías que se reparten el panorama mental del europeo medio, como lo eran liberalismo, socialismo, fascismo, nazismo y comunismo, cada una incluso con gobiernos estatales respaldándola. Aunque sí es posible que de ese desencanto pueda llegarse a actuaciones similares a la de Breivik.

${ }^{23}$ Serbeto, E.: "Morten Hoglund: "Nos entristece que haya militado en nuestro partido"”, $A B C$, 27 de julio de 2011, en

http://www.abc.es/20110727/internacional/abci-entrevista-diputado-noruega-201107270106.html.

${ }^{24}$ Véase Gellman, Barton: "The Secret World of Extreme Militias", Time Magazine U.S., 30 de septiembre de 2010, en http://www.time.com/time/magazine/article/0,9171,2022636,00.html. Según se desprende de este texto, el movimiento de extrema derecha en EEUU está fragmentado. Por una parte, existen milicias que se entrenan para velar por lo que creen correcta interpretación de la Constitución, que se consideran autodefensivas y patriotas, que resisten a una posible tiranía defendiendo el derecho a portar armas y criticando la obligación de pagar impuestos al gobierno central. Desde esa base común, algunos inciden más en el Posse Comitatus (nuevas milicias de 1970), otros son milenaristas cristianos y otros creen en peregrinas teorías conspirativas en las que el gobierno central sería un títere de algún poder oculto que busca alterar el orden mundial. Por otra, los suprematistas tienen una posición más activa, y se caracterizan por realizar atentados más extremas. Un ejemplo 
político (edificio del FBI), con un método típico, el coche bomba. Mc Veigh podría decirse que actuó creyéndose parte de un movimiento existente. ¿Existe un movimiento político del que sea parte Breivik? No. Comparte rasgos con partidos de extrema derecha europeos, pero ninguno de éstos propugna, al menos abiertamente, ataques terroristas como táctica.

El movimiento del que quiere ser parte es, pues, un movimiento ficticio, sectario, y ese sentido le liga al atentado con gas sarín de la secta japonesa Aum Shimrikyo, en el metro de Tokio, en marzo de $1995^{25}$. Esa perspectiva adolescente de ejecución casi indiscriminada ${ }^{26}$ que se inviste de representatividad política, de un proyecto político extremadamente irrealizable, lo acercaría, al otro extremo de la línea norteamericana citada, en el que se encuentra John Allen Muhammad, ciudadano de EEUU convertido al Islam y autor de una serie de asesinatos a personas que no tienen absolutamente nada que ver con el poder político y que ni siquiera están en edificios o lugares que son objetivos simbólicos. Se les asesinó por ser estadounidenses blancos. Hasta ahí, podría ser un asesino en serie. Pero el salto político lo dio su objetivo: Tenía un plan, delirante, nihilista, de colapso de ciudades ${ }^{27}$, lo que le une al caso Breivik. Así, el proyecto de Muhammad era inviable, imposible de concretar, incluso más difícil que el de Breivik, y en el caso del estadounidense se dificulta la emulación por la precariedad de la organización (francotiradores en furgoneta, frente a la logística del noruego) y apenas existe efecto propagandístico (confesión del plan ante el tribunal frente al Manifiesto), pero ambos posibilitan trazar una línea bastante definida respecto a acciones similares. Por ejemplo, tienen un matiz político, aun tenue, lo que supone una diferencia con otras acciones que no pueden considerarse políticas, como por ejemplo, los seis asesinatos de Alfredo Galán entre enero y marzo de $2003^{28}$.

A su vez, también se distinguen de atentados como los de Mohamed Merah en Toulouse y Montauban (Francia) los días 11, 15 y 19 de marzo de 2012 y que dejaron siete muertos ${ }^{29}$. En este caso, el modus operandi puede parecer el de un "lobo solitario", pero dado que existe una cobertura no sólo ideológica, sino también logística de la organización Al Qaeda, la doctrina no lo considera con esa etiqueta, sino como un terrorista que actúa individualmente en el marco del "polimorfismo propio del actual terrorismo global" ${ }^{30}$. El lector podrá preguntarse qué diferencia de naturaleza hay entre atentados como el de Muhammad y el de Merah: ¿Sólo el número de víctimas? En cierto modo, pero al igual que la guerra es algo más

es el atentado abortado de James Cummings, en 2008, que en un actuar muy similar a Breivik, esto es, poniendo todos sus recursos económicos al servicio de un gran atentado y valiéndose de una manera de comprar "creativa" y legal, había obtenido material suficiente para provocar un atentado con material radioactivo.

${ }^{25}$ EFE: "Japón captura al último fugitivo del atentado con gas sarín en Tokio en 1995", $A B C, 15$ de junio de 2012, en http://www.abc.es/20120615/internacional/abci-japones-sarin-arrestado-201206151113.html.

${ }^{26}$ Aunque atentó contra las oficinas del gobierno y buscaba matar a la ex presidenta noruega, y su ataque tuvo lugar en un campamento del partido laborista, y sus objetivos teóricamente son políticos según su manifiesto, también en éste predomina la indiscriminación, como el establecimiento de las citadas cuotas, o la manera de actuar en Utoya. Véase De Cózar, Álvaro y Gómez, Juan: "79 minutos con Anders Behring Breivik matando", El País, 31 de julio de 2011,

http://www.elpais.com/articulo/reportajes/79/minutos/Anders/Behring/Breivik/matando/elpepusocdmg/2011073 1elpdmgrep_1/Tes.

${ }^{27}$ Mount, Harry: “The sniper's plan: kill six whites a day for 30 days”, The Telegraph, 25 de mayo de 2006, http://www.telegraph.co.uk/news/worldnews/northamerica/usa/1519411/The-snipers-plan-kill-six-whites-a-dayfor-30-days.html.

${ }^{28}$ Lázaro, Julio M., "El Supremo confirma 142 años de cárcel al 'asesino de la baraja'”, El País, 11 de marzo de 2006, en http://elpais.com/diario/2006/03/11/madrid/1142079864 850215.html.

${ }^{29}$ Mora, Miguel: "Vida y muerte de un pistolero", El País, 25 de marzo de 2012, en http://internacional.elpais.com/internacional/2012/03/24/actualidad/1332611864 872531.html.

${ }^{30}$ Reinares, Fernando: “¿Un lobo solitario”, El País, 21 de marzo de 2012, en

http://internacional.elpais.com/internacional/2012/03/21/actualidad/1332349451_137202.html. 
que una serie de asesinatos, para encontrar el matiz diferencial son válidas las tres lógicas que Robert Pape usa para analizar las campañas de los terroristas suicidas: estratégica, social e individual $^{31}$.

La lógica estratégica de los terroristas individuales no inspirados por una organización ya establecida es vaga: a medida que más se diferencia su ideología de las de organizaciones ya existentes, más indiscriminados son los objetivos y la manera de actuar más similar al crimen ordinario. En los atentados de Merah podría decirse que hay una campaña detrás y todos los objetivos son simbólicos, que buscan un cambio en el gobierno (también en Mc Veigh y en Breivik); en cambio, en el de Muhammad, no se buscaba ningún rédito político, ni siquiera propagandístico. Sólo "colapsar" las ciudades, lo que está en el límite entre el crimen y la violencia política, si se considera el nihilismo una versión del anarquismo. Respecto a la lógica social, los terroristas individuales respaldados por una ideología aglutinante reciben más apoyo (normalmente respecto a los objetivos) que aquéllos que son vistos como ajustes de cuentas particulares o una manera de desencadenar hechos sin base real alguna, como en el caso de Muhammad; además de tener un proyecto de organización social posible. Finalmente, la lógica individual es, como es obvio, la determinante en los atentados llevados a cabo por un solo sujeto. Por ejemplo, Breivik y Mc Veigh condicionaron sus intereses individuales al éxito del objetivo (al igual que Merah), con una preparación que se prolongó a lo largo del tiempo y trabajando las bases ideológicas para que el efecto propagandístico del atentado fuera mayor. En cambio, en los asesinatos de Muhammad sólo intervino su odio a Occidente, e incluso el intento de enmascarar el asesinato de su mujer en otros asesinatos, para que pareciera azaroso y no se le acusara cuando se produjera, lo que hace indistinguible su proyecto político nihilista del interés personal; además, carece de una preparación para la realización de los atentados y no buscó réditos propagandísticos.

La citada implacabilidad es la que llevó a Breivik a establecer una casuística del terror es inquietante en términos morales y de seguridad. Reflexiona sobre otros tipos de terrorismo o actos de sabotaje, y ofrece un do it yourself para el occidental medio que quiera ser terrorista $^{32}$. Su manifiesto proporciona detalles sobre cómo realizar los atentados o cómo financiarlos, da consejos a terroristas sobre cómo aguantar física y psicológicamente antes y durante la acción, y se pone a sí mismo como ejemplo práctico para superar los problemas de preparar atentados de esa índole ${ }^{33}$. Todo ello con una vocación global, ya que opta por escribirlo en inglés antes que en noruego. Los preparativos aparecen detallados, por lo que prima el narcisismo o la propaganda, antes que la causa política, pues con ello se ayuda a los servicios de seguridad. Este manual de autoayuda para terroristas se dirige al occidental medio, al que aconseja cómo puede pasar desapercibido ante los cuerpos de seguridad mientras prepara el atentado y qué medios tienen para conseguir los materiales, cómo

\footnotetext{
31 "Primera: ¿cuál es la lógica estratégica del terrorismo suicida? Es decir, ¿por qué el atentado suicida tiene sentido político desde la perspectiva de una organización terrorista? Si las organizaciones terroristas no creyeran que los atentados suicidas suponen un avance en sus objetivos políticos, no los cometerían.

Segunda: ¿cuál es la lógica social del terrorismo suicida? ¿Por qué los atentados suicidas reciben un apoyo masivo en algunas sociedades y no en otras? Sin el apoyo social de la comunidad nacional de los terroristas, no se sostendrían las campañas terroristas suicidas.

Tercera: ¿cuál es la lógica individual del terrorismo suicida? ¿Qué induce a determinadas personas a renunciar a la propia vida para llevar a cabo atentados terroristas? Sin un contingente de terroristas potenciales dispuestos a intervenir, el alcance de las campañas de terrorismo suicida sería mucho menor". Pape, Robert A. (2006): Morir para ganar. Las estrategias del terrorismo suicida, Barcelona, Ediciones Paidós Ibérica, S.A, p. 36. Cursivas en el original.

32 "2083. Una Declaración Europea de Independencia”, op. cit., pp. 1415-1472.

${ }^{33}$ Ibid., pp. 1421 y ss, donde escribe sobre cómo obtuvo su armamento.
} 
realizarlos, además de qué objetivos atacar ${ }^{34}$. Se conocen otros textos en los que aparecen este tipo de descripciones ${ }^{35}$, pero suelen ser consensuados, un manual de una organización al que se accede tras un proceso. En el caso de Breivik se deja todo hecho para que cualquiera con la preparación mental adecuada prepare un atentado similar. Eso es un salto, ya que no sólo es un "lobo solitario" que pretende dirigirse a otros "lobos solitarios" (a partir del interrogante de si la sociedad ofrece herramientas para lograr una red de "lobos solitarios") sino a gente normal ${ }^{36}$.

Caracterizado como un "Caballero Justiciero", de estética paramilitar y, lo tragicómico, de súpervillano de cómic, que actúa en nombre de una proto organización, paralela a algunas pasadas (orden militar de los templarios ${ }^{37}$ ) y que servirá de propaganda de algunas futuras que se supone nacerán por sus actos, la idea que tiene Breivik de organización es de la suficiente ambigüedad para no ser nada o ser el principio de cualquier cosa. De ahí nace su convicción de que es posible, e incluso más letal, actuar en solitario o en pareja. Esto presenta rasgos similares al guevarismo, sustanciado en la frase de Regis Debray de que la guerrilla es el embrión del partido. Richard Gillespie, al hablar de la guerrilla urbana en Sudamérica, recuerda que muchos militantes creían que "actuaría como un catalizador para acelerar los procesos sociales y políticos que conducen a la revolución, expondría la naturaleza corrupta y opresiva de los regímenes desafiados, a la par que ganaría el apoyo de las masas demostrando la vulnerabilidad de las fuerzas del Estado",38. El término "open source warfare",39 recuerda a la espontaneidad preconizada por el ex líder del Partido Comunista de Brasil, Carlos Marighela $^{40}$. Sin embargo, la acción de Breivik se pretende, recordémoslo, no como parte de una campaña ya empezada, sino como el "pistoletazo de salida" de una campaña que se engrosará en el futuro.

Así, lo que podría denominarse "test de Wilkinson" "41 daría como resultado que Breivik cometió un acto aislado, preinsurreccional, sin apoyo popular y espasmódico, pero de gran

\footnotetext{
${ }^{34}$ Por ejemplo, en Ibid., p. 1471, explica cómo, a partir de lo que ha aprendido, acortar de 80 a 30 días la fase final de preparación de un atentado como el suyo.

35 Aust, Stefan y Schnibben, Cordt (2002): 11 de septiembre. Historia de un ataque terrorista, Barcelona, Galaxia Gutenberg Círculo de Lectores, pp. 342-357.

${ }^{36}$ Véase "2083. A European Declaration of Independence”, op. cit., pp. 927-929 y 952 y ss. "Aunque es verdad que el manifiesto insiste en las bondades de trabajar solo y no fiarse de nadie, ni de los familiares o amigos más íntimos (hasta aconseja hacerse pasar por gay para justificar toda clase de rarezas, como la tendencia a desaparecer durante días sin dar explicaciones), también se llega a un detalle casi obsesivo en la fijación de pautas organizativas. Breivik está visiblemente familiarizado con las leyes de la clandestinidad y con trucos de espías para comunicarse sin dejar rastro en Internet"; Grau, op. cit. Sin olvidar la versión agitprop del Manifiesto, en Breivik Video Manifesto-Norway, TwitVid, en http://www.twitvid.com/EXJWW.

${ }^{37}$ Para un análisis de la capacidad que el referente mitificado de los templarios posee para la construcción de un "parentesco ficticio" o unidad de grupo autoconsiderado como único para trascender ciertos valores, véase Robb, John: "Knights Templars Norway/Mexico", Global Guerrillas, 25 de julio de 2011, en http://globalguerrillas.typepad.com/globalguerrillas/2011/07/journal-knights-templar.html; Sobre el grupo de Los Caballeros Templarios, una organización criminal mexicana que opera en la actualidad principalmente en el Estado de Michoacán y que también alude en su ideología a esa orden medieval, véase Corcoran, Patrick, "Inside The Moral Code of the Caballeros Drug Gang", In SightCrime, 20 de julio de 2011, en http://www.insightcrime.org/news-analysis/inside-the-moral-code-of-the-caballeros-drug-gang.

${ }^{38}$ Gillespie, op.cit., pp. 193-194.

39 “2083. A European Declaration of Independence”, op. cit., pp. 840 y ss.

40 "Pequeñas organizaciones autónomas, militantes revolucionarios y francotiradores a título individual, se unen a nuestra organización con absoluta libertad de acción, siempre que acepten, defiendan y cumplan sin reservas con todos nuestros principios estratégicos y tácticos"; Gillespie, op. cit., p. 196.

41 "En todo análisis digno de consideración de una campaña terrorista específica, es esencial, por supuesto, tomar en cuenta el contexto político, histórico y cultural específico, así como la ideología y objetivos de los grupos implicados. Es necesario interpretar el papel y la efectividad del terrorismo en el desarrollo global de cada
} 
daño y efecto propagandístico. De nuevo, el análisis de Juergensmeyer para el terrorismo religioso es válido, pues sus actos "pretenden ilustrar o referirse a algo que está más allá de sus objetivos inmediatos: una conquista mayor, por ejemplo, o una lucha más impresionante de lo que parece" ${ }^{42}$. Esta lucha que se pretende universal ha sido potenciada por la globalización. El análisis general que hace Breivik para justificar su acto incluye casi todos los rincones del planeta, e involucra a todos los europeos. Es una situación de (ficticia) guerra continental $^{43}$. Rasgos de la globalización como el inglés como lengua franca, la multiplicación propagandística del terrorismo realizado por los mass media, la facilidad para comprar armamento que hace décadas estaría vedado a los civiles, con la correlativa posibilidad de que cualquiera se entrene por su cuenta para ser un soldado de elite, son características presentes en Breivik. De hecho, la intensidad del ataque es similar al de los atentados de Bombay de $2008^{44}$, es decir, actos terroristas, vagamente relacionadas con un objetivo político, en los que se combinan acciones de diferente intensidad, pero que en su conjunto remiten a un ataque militar ${ }^{45}$.

\section{Consecuencias para la seguridad: ¿Qué nuevo paradigma? ${ }^{46}$}

Podría decirse que, al igual que la muerte de Osama Bin Laden en Pakistán tiene un simbolismo positivo, pero mantiene los desafíos que representa Al Qaeda, el doble atentado de Noruega tienen un simbolismo negativo, y actualiza los desafíos que las fuerzas de

conflicto en el que aparece. ¿Se lo usa como un arma auxiliar en una estrategia más amplia de guerra revolucionaria o bien aisladamente de un modo preinsurreccional? ¿Qué grado de apoyo popular tienen los ejecutores de las acciones terroristas, si es que tienen alguno? ¿En qué grado es severa y prolongada la violencia? ¿Es solamente espasmódica y de pequeña escala la destrucción causada? ¿O crece en intensidad, frecuencia y carácter mortífero, hasta el punto de que amenaza con desencadenar una guerra civil de grandes proporciones?" Wilkinson, Paul: "La lucha contra la hidra: El terrorismo internacional y el imperio de la ley", en O'Sullivan, op. cit., pp. 256-257.

42 Juergensmeyer, op.cit., p. 142.

43 "La idea de estado de guerra supone más que una actitud; en último término es una visión del mundo y una afirmación de poder. Vivir en un estado de guerra es vivir en un mundo en el que los individuos saben quiénes son, por qué han sufrido, por qué mano han sido humillados y a qué coste han perseverado. El concepto de guerra aporta visiones cosmológicas, históricas y escatológicas y ofrece las riendas del control político. Y quizá lo más importante, detenta la esperanza de una victoria y los medios para lograrla. En las imágenes de guerra cósmica, este triunfo victorioso es un gran momento de transformación personal y social, que trasciende todas las limitaciones del mundo. Uno no abandona fácilmente esas expectativas. No disponer de esas imágenes de guerra es casi como no tener esperanzas"; Ibid., pp. 180-181.

${ }^{44}$ Figueras, Amanda: "Así fue el asalto a Bombay: Terroristas adiestrados como soldados de élite”, El Mundo, 29 de noviembre de 2008 , en http://www.elmundo.es/elmundo/2008/11/28/internacional/1227885894.html.

${ }^{45}$ De hecho, la descripción que se aplicó a estos ataques encaja con la actuación de Breivik: "una nueva modalidad de terror: jóvenes que actúan como una fuerza policial especial, muy bien entrenados, con armas de precisión, y con gran determinación para lograr sus objetivos"; Ibid.

46 "P. Breivik fue militante del Partido del Progreso (FRP) entre 1999 y 2007, un grupo con algunos puntos de vista de extrema derecha. En Alemania un partido legal puede ser vigilado por los servicios secretos...

R. Esto es Noruega, aquí no se vigila a partidos legales. Alemania tiene otra historia, otros problemas y otras leyes.

P. ¿Tienen informantes dentro de los partidos extremistas que les alerten sobre posibles elementos radicales?

R. No los tenemos. Esto es Noruega y el Partido del Progreso es legal y respetuoso de la ley"; Gómez, Juan: "Entrevista: Janne Kristiansen, Jefa del servicio secreto noruego: No hay indicios que demuestren que Breivik tuviera cómplices", El País, 29 de julio de 2011, en

http://www.elpais.com/articulo/internacional/hay/indicios/demuestren/Breivik/tuviera/complices/elpepiint/20110 729elpepiint 5/Tes. 
seguridad deben afrontar para la actuación contra individuos que emergen, aparentemente de la nada.

Los atentados de Oslo y Utoya ejemplifican que en Europa pueden cometerse atentados por un "lobo solitario" de extrema derecha en un país considerado modelo en derechos y libertades. Es pronto para afirmar que haya un cambio de tendencia en el terrorismo occidental $^{47}$, como lo hubo del que tiene motivos secesionistas (IRA, ETA), al islamista, pero sí que debe ponerse énfasis en prevenir este terrorismo.

La seguridad se enfrenta al desafío de todo terrorismo, que lleva aparejado un punto imprevisible. Cada atentado terrorista exitoso hace preguntarse a las fuerzas de seguridad no sólo qué ha fallado, sino si podía preverse. A veces, el atentado es tan devastador que obliga a un cambio de paradigma. Si los terroristas secuestraban un avión exclusivamente para retener a los pasajeros y exigir que se cumplieran sus demandas, ¿cómo es que unos secuestradores usan un avión como arma, para estrellarlos contra objetivos simbólicos? ¿Cómo es que los terroristas calculan los efectos que pueden tener en la opinión pública y cortocircuitar la jornada previa a unas elecciones? ¿Cómo es que un individuo actúa como si estuviera en guerra contra un país sin conflictos violentos desde la Segunda Guerra Mundial, y obliga así a plantearse si el terrorismo en Europa ha pasado de "los islamistas pueden hacer cualquier cosa" a "cualquiera puede hacer cualquier cosa"?

Es decir, en el análisis de un posible atentado, según Montero Gómez, continúa estando presente dos defectos: politización e incapacidad para procesar adecuadamente escenarios de incertidumbre ${ }^{48}$. Hasta el caso Breivik, se consideraba que sólo el terrorismo islámico podía

\footnotetext{
${ }^{47}$ Munayyer, Yousef: "Lessons drawn from the blonde bomber", Al Jazeera, 26 de julio de 2011, en http://english.aljazeera.net/indepth/opinion/2011/07/2011726861255428.html. Se cita ejemplos de estadounidenses como el de Lucas John Helder, que envió paquetes bomba 2002 con el absurdo objetivo de dibujar una cara sonriente desde el cielo; Jim Adkisson, que tiroreó a miembros de una congregación durante una actuación musical, en 2008; Andrew Joseph Stack, que en 2010 protagonizó un ataque suicida contra los edificios de Echelon en Austin; o Jared Lee Loughner, autor del tiroteo de Tucson, donde resultó herida un congresista demócrata. Quizá sí pueda defenderse con más consistencia, pero igualmente con interrogantes, que hay un cambio a que el modus operandi elegido sea el de los "lobos solitarios": "En una obra igual de voluminosa que el manifiesto de Breivik, la Llamada a la resistencia islámica global (publicada en internet en enero de 2005), el sirio-español Mustafa Setmarian animaba a que la siguiente fase de la yihad estuviese protagonizada por individuos y grupos independientes que atentasen por cuenta propia. En los últimos años, tanto Al Qaida central como Al Qaida en la Península Arábiga han alentado a sus simpatizantes en Europa y Estados Unidos a actuar de igual manera". Jordán, op. cit.

${ }^{48}$ Montero Gómez, Andrés: "Psicología de la inteligencia contraterrorista", en Navarro Bonilla, Diego y Esteban Navarro, Miguel Ángel (coords.) (2007): Terrorismo global. Gestión de información y servicios de inteligencia, Madrid, Plaza y Valdés S.L, pp. 26-28. "[Lo que ] Lowenthal denomina 'la lucha contra lo increíble', [implica que] las cosas son más complejas si cabe, pues se relacionan íntimamente con la previsión cualititativa y con los escenarios culturalmente aceptables. Este tipo de previsiones, que a diferencia de las predicciones meteorológicas no están basadas en cálculos matemáticos, están dedicadas a conocer futuros probables y posibles a partir de análisis conceptuales y de significados, es decir, a describir el comportamiento de un fenómeno complejo y a trazar su evolución y tendencia. El objetivo sería, de esta manera, anticiparse con acciones a un punto determinado de la tendencia evolutiva de un problema, i.e., el terrorismo, cortocircuitando su desarrollo (represión preventiva, lo han bautizado, y empezado a aplicar en Iraq). Sin embargo, la utilización de herramientas para el análisis cualitativo era tan precaria en 1993 como ahora. A pesar de que desde mucho antes se cuenta con técnicas como la de escenarios, que permite construir futuribles a partir de una combinación precisa de indicadores, son del todo escasos los analistas realmente capacitados para implementarla y los políticos preparados para consumir los informes de ella derivados. A ello añadimos la dificultad de los propios analistas para valorizar piezas de información muy novedosas (por ejemplo, contextualizar adecuadamente indicios que le decían al FBI que cierto número de personas tomaban clases de vuelo dentro de los propios EEUU) cuya combinación analítica resulta en combinaciones concluyentes que parecen increíbles (estrellar aviones contra las Torres Gemelas) para los modelos mentales sesgados del propio analista, incapaz de liberarse
} 
atacar en Europa, y que, de haber otro tipo de terrorismo sólo determinados países (los más conflictivos) serán objeto de tal violencia, violencia que presentará características ya previstas. Sin embargo, esto no es así. En una Europa convulsa económicamente y sin norte ideológico por una crisis de legitimidad que afecta a gobiernos y a la UE, los actos contestatarios masivos (sean pacíficos, como el $15 \mathrm{M}$, sean violentos, como el vandalismo inglés de agosto 2011) o individuales (atentado de Breivik) van a repetirse. Lo cierto es que Breivik, como se ha dicho, ha revelado a las fuerzas de seguridad los pasos a seguir para convertirse en un terrorista, lo que debería reducir la posibilidad de nuevos atentados similares. Atentados así tienen en su mal su bien: A partir de ahora, es de esperar que se realicen labores de vigilancia, monitoreo, infiltración, en grupos que comparten ideas con Breivik. No sólo eso, sino que también debería reparar los agujeros legales que han ayudado a que un atentado de ese tipo saliera tan bien: la facilidad respecto a la compra de armas por Internet, etc, debería llevar a algún tipo de medida ${ }^{49}$.

Pero al margen de estas conclusiones, surge la pregunta de si el atentado de Breivik supone la necesidad de repensar el panorama de la seguridad europea, esto es, ¿qué nuevos escenario, nuevos incluso respecto a Breivik, puede encontrarse Occidente, dado que el signo de los tiempos es la continua innovación, también terrorista? ${ }^{50} \mathrm{Si}$ se usa la imagen de una pirámide, que se estrecha a medida que el proyecto de un terrorista es más inviable, tanto por la base social que consigue suscitar como por la dificultad intrínseca de sus objetivos, y cuyos eslabones se pueden intercambiar según los cambios históricos, abajo estarían organizaciones terroristas que buscan la independencia de territorios, como ETA, el siguiente nivel sería el de los grupos islámicos (dado que la retirada de EEUU de países musulmanes sí que es factible, si bien la instauración de un califato global lo es menos), posteriormente estarían los grupos de extrema izquierda, como los que actuaron en la posguerra de la Segunda Guerra Mundial (y en la transición española), que anteriormente lograban base social a causa del ejemplo de los numerosos países comunistas y que ahora lo logran con promesas de cambio social, luego los grupos de extrema derecha que actuaron en ese mismo período que sí han sido deslegitimados por su apuesta por conceptos como el racismo, y finalmente, como punta de la pirámide, los apocalípticos. Breivik pertenece a un punto intermedio entre las dos últimas categorías.

Decía Martin Amis que James Joyce había escrito el "Ulises" para un solo lector: James Joyce. Un nuevo paradigma del terrorismo puede consistir en que los sujetos a los que se busca adherir a la acción terrorista y los sujetos supuestamente beneficiados por ésta cada vez serán más abstractos, e incluso pueden llegar a ser contradictorios o... Irreales. Por ejemplo, la base social de Breivik es más pasada (templarios) y futura (quienes presuntamente reconocerán su valor) que presente ${ }^{51}$. El sujeto al que se ofrece el atentado y su objetivo

de sus creencias sobre cómo debe funcionar el mundo y hasta dónde es capaz de llegar la conducta humana"; Ibid., p. 28.

49 "30 rounds of insanity: gun accessories we don't need", The Wahington Post, 3 de agosto de 2011 en http://www.washingtonpost.com/opinions/gun-accessories-we-dont

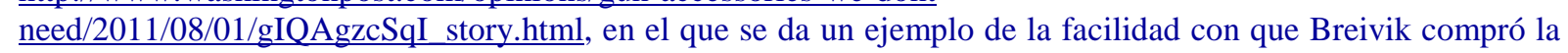
munición para su rifle semiautomático, supuestamente a un proveedor norteamericano.

${ }^{50}$ Alonso, Rogelio (2011): "La innovación terrorista: desafíos para la prevención y contención del terrorismo yihadista”, Documento de Opinión 08/2011, Instituto Español de Estudios Estratégicos, en http://www.ieee.es/Galerias/fichero/docs_opinion/2011/DIEEEO08_2011InnovacionTerrorista.pdf.

${ }^{51}$ Una de las claves del pensamiento de Breivik está en “2083. Una Declaración Europea de Independencia”, op. cit., pp. 1363-1364. Allí, se alude a que su defensa no es de la religión cristiana per se, sino de los valores culturales aparejados a la Europa (que ha sido históricamente) cristiana, por lo que se reafirma en una ambigüedad ideológica inherente (¿no son el marxismo o el multiculturalismo productos europeos?). También en esas páginas se remite en términos vagos, que él justifica por cuestiones de seguridad, a una supuesta 
estarían tan incontaminados, serían tan puros, que cualquier medio sería justo. En este sentido, Breivik muestra un escudo ideológico mayor incluso que quienes cometieron un atentado tan grave como el 11S. Éstos se remitían a campañas en marcha o idealizaban a sujetos reales, como la Umma. Pero Breivik mezcla imaginación con infantilismo, erudición con banalidad, medios concretos con el fanatismo de los que creen en algo superior, que sólo les susurra a ellos y que les absolverá de cualquier crimen. Su opción es declarar un conflicto asimétrico ${ }^{52}$, declararlo, sin intención ni siquiera de ganarlo, con independencia de que sea un eco o una alarma y creyendo, quizás sin fe, en que no sea un punto y final.

organización nacida en 2002 y del que él sería representante, lo que ilustra la irrealidad (¿deliberada?) de su base política presente.

52، La estrategia asimétrica trata de influir en la opinión pública, doblegar la mente de la población, influir en las decisiones políticas. El adversario que elija renunciar a los métodos convencionales y plantear un conflicto armado asimétrico tomará siempre como objetivos tanto a los dirigentes políticos como a la opinión pública, dejando a las fuerzas militares de su enemigo en un plano secundario. Este es un punto crucial para comprender la naturaleza de la estrategia asimétrica”. Ballesteros Martín, Miguel Ángel: “¿Qué es el conflicto asimétrico? Soluciones globales para amenazas globales", en Navarro y Esteban, op. cit., p. 77; "2083. A European Declaration of Independence", op. cit., pp. 834-835 y 1255-1256 de su Manifiesto, da una vuelta de tuerca a esto, al propugnar una estrategia de no ataque contra objetivos musulmanes, salvo en contadas ocasiones (si con ello se logra radicalizar a los musulmanes, esto es, con la espiral acción-reacción-acción). Su objetivo son los occidentales contrarios a sus ideas. 